\title{
Modelling dispersal of salmon lice in a large fjordic system: Loch Linnhe, Scotland
}

\author{
N.K.G. Salamaa ${ }^{\text {A.G. Murray }}{ }^{\mathrm{a}}$ and B. Rabe ${ }^{\mathrm{a}}$ \\ ${ }^{a}$ Marine Laboratory, Marine Scotland Science, 375 Victoria Road, Aberdeen AB11 9DB, United Kingdom \\ Email: sandy.murray@scotland.gsi.gov.uk
}

\begin{abstract}
Sea lice are marine ectoparasitic copepods that infect a wide range of fish and other species. Salmonid fish in their marine phase are infected by a variety of generalist Caligus species (in Scotland $C$. elenogatus) and the salmonid specialist Lepeophtheirus salmonis. Cost of salmon lice is estimated to be $€ 305 \mathrm{M}$ damage worldwide and have also been associated with declines in wild salmonid populations.
\end{abstract}

Sea lice undergo a planktonic larval phase that consists of two non-infectious naupliar stages and the infectious copepodid stage. During this planktonic phase the larvae are transported by marine currents and so it is of crucial importance for our understanding of how lice on different host populations may interact. This is important for protecting wild fish and for identifying groups of farms that would benefit most strongly from coordinated management.

We therefore are developing a model of the Loch Linnhe system in the western Highlands of Scotland using a modelling approach first developed for the smaller Loch Torridon system. Loch Linnhe is Scotland's largest sea loch (fjord) being more than $60 \mathrm{~km}$ long and containing 10 salmon farms operated by two companies. A coupled hydrodynamic-particle model is used to derive the distribution of lice under different environmental forcing. The hydrodynamic model used is POLCOMS with a $100 \mathrm{~m}$ horizontal resolution and 15 minute time-step in the first instance. This model is forced using tidal forcing at the mouth of the loch (Firth of Lorn and Sound of Mull), winds, and freshwater inputs from rivers and side lochs. The particle model describes the development of the larvae through the different stages and their mortality. Development rate is strongly temperature dependent; lice take about 3.6 days from hatching to become infectious at $10^{\circ} \mathrm{C}$ but much longer at lower temperatures. Mortality rate is highly sensitive to salinity, increasing rapidly once salinity drops below 29 ppt.

Initial results show that the larvae can be transported over large distances, sometimes 20-30 km from their source, before becoming infectious. Here they can form elevated but localised concentrations. Copepodids may be absent from their parents' hosts.

A sampling programme has been initiated to validate the model predictions. Data has been obtained for May 2011 and a second validation exercise is planned for October 2011; further validation data will be obtained in 2012 and 2013. The validation consists of the collection of hydrodynamic and forcing data, using plankton tows to detect larval lice (all phases), and sentinel fish to attract the infectious copepodids. The initial sampling was carried out in May 2011 under extremely difficult conditions of south-westerly winds reaching up to $85 \mathrm{mph}$. Despite this, planktonic tows were completed for 30 of the planned 31 locations, 9 out of 10 sentinel cages were recovered, and hydrographic measurements were taken. Useful data was thus obtained under poor weather conditions which give confidence that validation will be practicable under a representative range of forcing conditions.

The model will be used to evaluate where concentrations of lice form under observed environmental forcing and to advise on the management of salmon farms.

Keywords: Coupled hydrodynamic-particle models, salmon aquaculture, parasites 


\section{INTRODUCTION}

Scotland produces a tenth of the world's farmed Atlantic salmon (Salmo salar) at some 144,000 t (Walker 2010) making it the third largest salmon aquaculture industry globally with a farm gate value of over $£ 400 \mathrm{M}$ (SSP0 2011). It is Scotland's largest food export accounting for some $40 \%$ of trade. The industry also provides valuable employment to communities in remote and rural areas of the Highlands and Islands. Although Scotland's salmon aquaculture industry has a relatively high health status, production loss due to a range of diseases and parasites remain an issue such as salmon lice. Since the 1970s the extent of the problem has varied (Lees et al. 2008). Salmon lice consist of various Caligus species (in Scotland Caligus elongatus) with a broad host range, and Lepeophtheirus salmonis a salmonid specialist; this latter causes the more serious problem in Scotland. The control of lice on marine farmed salmonids is estimated to cost $€ 305 \mathrm{M}$ worldwide (Costello 2009) and in Scotland it is estimated at $€ 33 \mathrm{M}$. Sea lice have also been associated with impacts on population of wild salmonids such as pink salmon in Canada (Krkošek \& Hilburn 2011) and sea trout in Ireland (Gargan et al 2007).

Sea lice spread between hosts and host populations through a planktonic larval phase consisting of two naupliar phases (nauplii 1 and nauplii 2) and a copepodid phase. The non-feeding nauplii are largely passive, but are able to adjust their depth in the water column. The copepodids actively seek out hosts over short distances to parasitise and respond to a variety of signals such as shadows and semiochemicals that could indicate host presence. Over larger scales copepodids are also mostly passive, but can maintain their depth more effectively than the nauplii. Although larvae maintain their vertical positions copepodids can swim over several centimetres to find hosts. The time, and hence the distance, over which larval lice are transported depends on maturation and mortality rates. Maturation is dependent on temperature (lice take about 3.6 days from hatching to becoming infectious at $10^{\circ} \mathrm{C}$ but much longer at lower temperatures) whilst increased mortality occurs in lower salinity (increasing rapidly once salinity drops below $29 \mathrm{ppt}$ ).

Salmon aquaculture has increased the number of hosts available for lice to parasitise. Although farms apply a suite of reductive treatments to minimise the resulting female numbers and subsequent number of offspring, it is important to ascertain where these planktonic lice are transported.

Marine Scotland Science (MSS) has previously developed a model for lice dispersal in Loch Torridon (Amundrud \& Murray 2009). This model has been amended here and used to simulate dispersal for a much larger system containing more fish farms. Loch Linnhe is Scotland's largest sea loch (fjord) being over $60 \mathrm{~km}$ long from its mouth at the Sound of Mull and Firth of Lorn to its head near Fort William (Fig 1a). The loch is orientated south-west to north-east and therefore catches the prevailing south-westerly winds (Fig 2a). Surrounded by high ground, including Scotland's highest mountain (Ben Nevis) at its head, this helps funnel winds along the loch and makes it more difficult to predict these localised winds. Loch Linnhe connects to a number of inner lochs including Loch Eil, Loch Leven, Loch Creran, Loch Etive, and Loch A'Chore, which, in addition to rivers, contribute freshwater to the system.
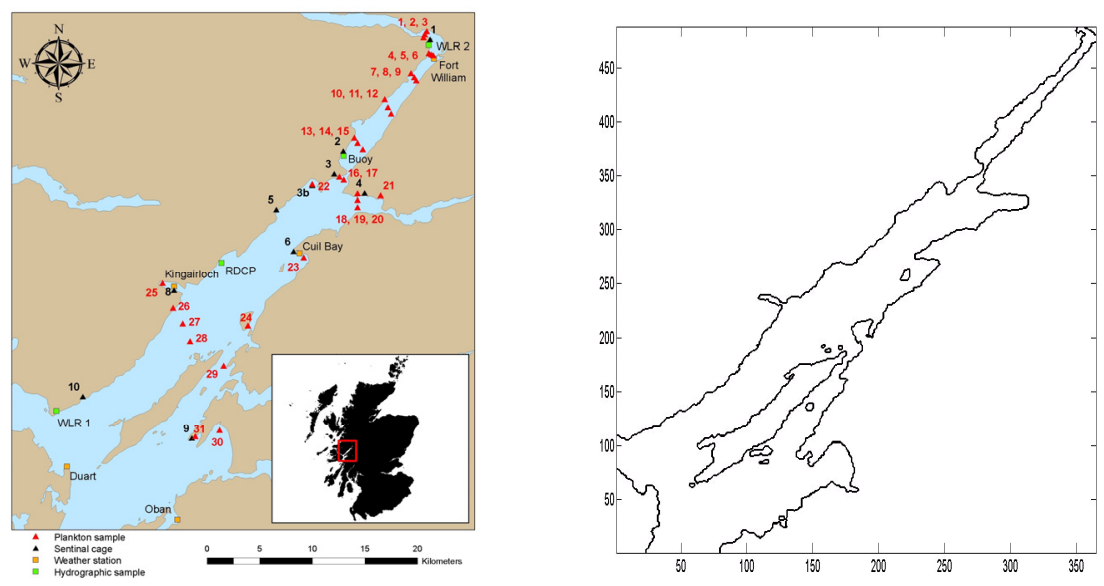
Fig 1. a) The location of Loch Linnhe on the west coast of Scotland and the range of biological and oceanographic sampling stations used for model output validation. WLR are water level recorders, RDCP is a Doppler Current Profiler, the buoy is a multi-parameter buoy, and hydrographic stations measuring temperature, conductivity (salinity) and pressure follow the plankton sample locations with additional cross-sections not marked on the map. b) The model outline of the Loch Linnhe system

Loch Linnhe contains ten salmon farms operated by two companies. These farms have a combined consented on site biomass of $13270 \mathrm{t}$ on a coordinated two year production cycle complete with a loch-wide fallowing. This means, since salmon lice are entirely marine, that when the production cycle starts the farms are lice-free and must be infected from outside or from wild fish.
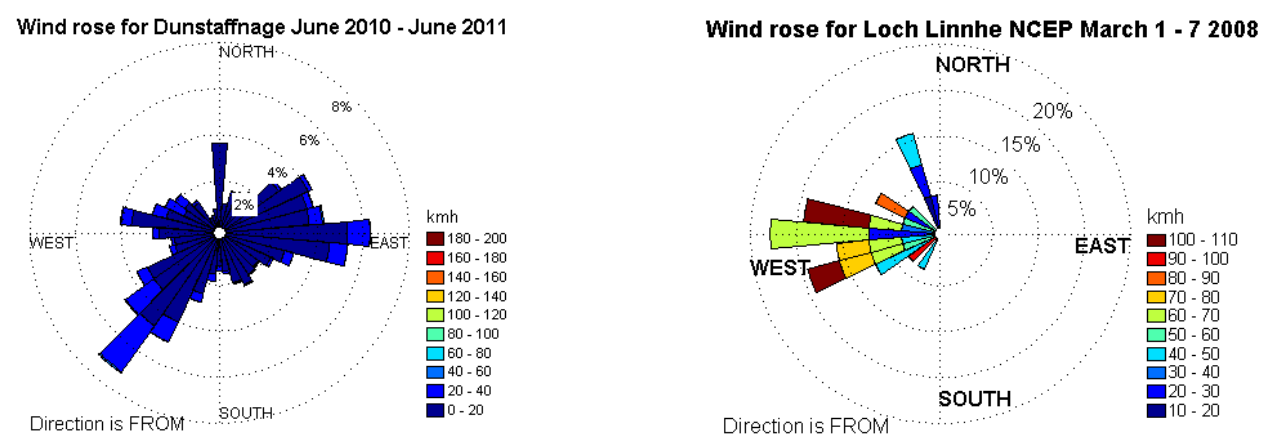

Fig 2a). The yearly wind rose demonstrating the prevailing south-westerly winds obtained from June 2010 to June 2011 at Dunstaffnage on the east bank of Loch Linnhe and b) the wind rose for $1^{\text {st }}-7^{\text {th }}$ March 2008 for Loch Linnhe from NCEP data showing the westerly winds forcing the initial model runs (data provided by SAMS).

\section{THE HYDRODYNAMIC MODEL OF LOCH LINNHE}

The Scottish Association for Marine Science (SAMS) applied POLCOMS, the Proudman Oceanographic Laboratory developed three-dimensional hydrodynamic coastal ocean model, to the Loch Linnhe system (see model domain in Fig. 1b). The baroclinic model has a $100 \mathrm{~m}$ horizontal resolution, a variable vertical resolution with smaller steps in surface and bottom boundary layers (s-coordinates), and 15 minute time intervals in the first instance for the outer and inner Loch Linnhe (Fig 1b). Key components of the model drivers are freshwater inputs from rivers and adjoining lochs, tides defined by tidal diamonds at the boundaries (Firth of Lorn and Sound of Mull), and wind, which initially is defined as winds from NCEP from the first week in March 2008 but will be measured winds throughout the loch during validation periods for future runs.

The model is able to resolve the distribution and fluxes of surface layer properties. It has been demonstrated that temperature and salinity estimates based on long term data do not differ significantly from the model predictions, suggesting that the characteristics of the system are captured by the model domain and properties. There is some minor discrepancy between model and actual topography due to the application of a $100 \mathrm{~m}$ grid structure causing certain features and characteristics of the Loch to be simplified.

Similar models for Scottish sea lochs have demonstrated accurate patterns of wind forced hydrodynamics. Although the model can produce three-dimensional resolution, previous work has demonstrated that the majority of lice reside in the surface layer (Hervøy et al., 2003); therefore the vertical resolution was limited to the upper $5 \mathrm{~m}$. The surface distributions of temperature and salinity, which is important to lice biology, respond to tides, wind, and freshwater inputs. The conditions produced by the model are being validated using oceanographic measurements of water level, currents, temperature, conductivity (salinity) taken from a range of positions in the system (see Fig 1a) at different times (1991, 2010, 2011). Measurements at the boundaries to represent tides more accurately were unsuccessful due to instrument failure. In addition to validation data collection during a fortnight in spring 2011, wind data was recorded at various locations around the loch to provide an alternate set of variable forcing conditions for ongoing model simulations. 
Here we use NCEP wind data from $1^{\text {st }}-7^{\text {th }}$ March 2008 to force an example model scenario. The prevailing winds during that time was from the West (Fig $2 \mathrm{~b}$ ).

\section{PARTICLE MODELLING}

The particle model is essentially that described by Amundrud and Murray (2009) and as presented at MODSIM 2007 by Murray and Amundrud (2007) applied to a larger system. The vectors produced by the hydrodynamic model are used to drive modelled movements of particles representing planktonic lice. As the particles are transported their condition is altered representing maturation and mortality.

To date lice sources in the model are defined as fish farms within the Linnhe system. Currently field work is being conducted to ascertain where wild sources are located as they may represent important sources of lice which re-infect farms after treatment (Penston \& Davies 2009). Each time-step a default number of particles could be released from the source, and this number is weighted dependent on farm consented biomass. This process would require tracking the position of each of the tens of thousands of particles released over a one or two week period. Each of these thousands of particles represents many lice and the number of particles used is simply a trade-off between output resolution and computational requirements. Here we provide an example scenario where there is a release of 1500 particles from a source in the system on the $1^{\text {st }}$ March 2008.

The location of each of the particles is driven by the velocities produced by the hydrodynamic model. The particle tracking model is a $4^{\text {th }}$ order Runge-Kutta solver for the Lagrangian equation of motion:

$$
p\left(x_{i+1}, y_{i+1}\right)=p\left(x_{i}, y_{i}\right)+u(x, y) \Delta t+\sqrt{6 R D_{h} \Delta t}
$$

Where $p\left(x_{i}, y_{i}\right)$ is the particle position as a function of $x$ and $y$ at time $i, u(x, y)$ is the velocity as a function of $x$ and $y, \Delta t$ is the time step, $R$ is a random uniformed distribution value between $[-1,1]$ to introduce a randomwalk stochastic element, and $D_{h}$ is the diffusivity set at $0.1 \mathrm{~m}^{2} \mathrm{~s}^{-1}$. Surface velocities are calculated using linear interpolation with time and the square root of distance between the $x$ and $y$ vectors. At the boundaries and where the model domain meets land the particles are defined as sticking at that position, until exposed to a current that would transport it away from the shore, which is consistent for passively dispersed material in sea lochs, such that:

$$
p\left(x_{i+1}, y_{i+1}\right)=p\left(x_{i}, y_{i}\right)
$$

Particle density and age status is dependent on development rates as a function of temperature (T). The model of Stein et al. (2005) describes the time to become an infectious mature particle $\left(t_{\mathrm{m}}\right)$ as:

$$
t_{m}=\left[\frac{24.79}{(T-10)+(24.79 \times 0.525)}\right]^{2}
$$

At $t_{\mathrm{m}}$ and each subsequent time interval, particles have a default rate of $10 \% \mathrm{~h}^{-1}$ of becoming an infectious copepodid. Maturation is approximately 9.6 days at $5^{\circ} \mathrm{C}, 3.6$ days at $10^{\circ} \mathrm{C}$, and 1.9 days at $15^{\circ} \mathrm{C}$. Mortality is dependent on salinity, increasing rapidly as salinity drops to less than $29 \mathrm{ppt}$ (Bricknell et al. 2006). As much of the system is sea water, mortality of lice is set at a default decay $(d)$ value of $1 \% \mathrm{~h}^{-1}$ (Johnson \& Albright 1991). Therefore the relative value of each particle $(P)$ depends on the product of $i$ and $d, P_{0}$ is assigned as 1 


$$
P_{t}=P_{0} e^{-d i}
$$

The combined modelling process is used to obtain particle distribution fields from sources of lice and hence identifies areas at risk of interaction between lice and salmon under known wind conditions.

\section{INITIAL RESULTS}

Initial simulation results from single point releases (all particles released within first hour) indicate that lice are able to be transported up to distances of $30 \mathrm{~km}$ before becoming infectious. However, the model simulations demonstrate that it could be the case that transmission of particles could occur above distances of $10 \mathrm{~km}$. Furthermore, the simulation results demonstrate that lice dispersal patterns do not necessarily result in connective hydrodynamic pathways between nearest neighbour farms.

It is assumed that the predominantly westerly wind forcings between years in 2008 could be considered to produce similar distribution characteristics which can be assessed by recent field sampling of planktonic and infectious lice under westerly and southwesterly winds. A scenario forced by the specific wind conditions spring 2011 is being undertaken, but is not yet completed.

These runs have been used to assess potential patterns of larval lice dispersal and to identify locations where lice larvae are likely to accumulate. This has been used to design a field work programme such as locations for plankton tows and sentinel cages. An example result is illustrated for the dispersal patterns for particles representing nauplii and copepodids transported from one farm (Fig. 3).
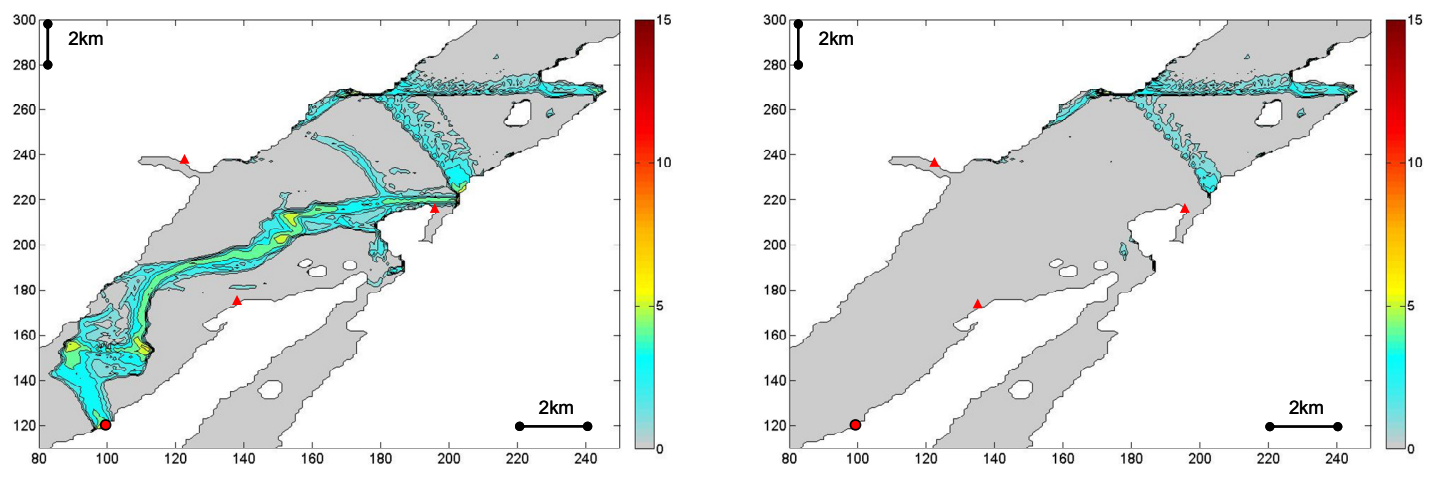

Fig 3. An example of simulated distributions and relative densities of particle from a source farm showing transmission over a $30 \mathrm{~km}$ distance for a) planktonic larvae and b) copepodids and nearby farms $\mathbf{m}$. The sum of all particles over time within each grid cell are shown.

The model is being validated under two specific observed scenarios for 2011. These are a spring sampling operation in May 2011, which has been undertaken, and an autumn sampling operation planned for October 2011. Further operations will be carried out in 2012 and 2013 with the aim of achieving a well validated model under a range of different environmental conditions. The validation consists of the accumulation of oceanographic data for the hydrodynamic model and biological data for the sea lice model.

The May 2011 sampling operation has been successfully completed. It was, however, undertaken under severe weather conditions with south-westerly winds of up to $85 \mathrm{mph}$ being channelled up the loch. This meant that the sampling regime was not carried out exactly as intended, however sampling was completed creating a good data set for model validation in extreme conditions, and giving confidence that field work can be used to obtain data for model validation even when conditions are poor. Oceanographic data consists of 21 CTD stations out of the 35 planned stations. Moorings are in the water from April to November 2011 measuring water level at the 
head and mouth of the loch, as well as one current meter, one multi-parameter buoy, and four weather stations on land around the loch for wind model forcing. The biological data consists of lice counts from farms, plankton tows for larval lice from 30 out of 31 stations, and 9 out of 10 cages stocked with sentinel fish to attract the infectious copepodids. The location of each of the sampling locations is highlighted in Fig. 1a.

Counts of lice on farms are being provided by the fish farms in the model domain. From this it will be possible to calculate the absolute contribution of each farm in terms of number released (rather than the relative numbers used to drive the initial modelling). Fish farmers sample their farms on a weekly basis for lice, with a standard sample being of 25 fish split into 5 fish from 6 cages. However, farmers have agreed to increase counts to 60 fish during the simulated periods, allowing a more accurate estimate of loads and hence production. Since numbers of mature females in such a sample may be very low, the total lice population in the sample and an analysis of distribution between development stages will be used to estimate the number of egg producing females on a farm.

Data on the distribution of wild salmonid fish is also being obtained with the help of the local fisheries trusts (Lochaber Fisheries Trust in the north of Loch Linnhe). This data will be useful for identifying sensitive areas in which lice concentrations could cause more problems were they to occur. The wild fish may also be an important source of lice for the initiation of infection in farms after they have been fallowed.

Although sentinel cages sample a small area of the loch, it is likely that that location can be described as being representative of the surrounding locality. Under this assumption the general predictions of the model are supported by lice counts from sentinel fish with sentinel cages located in areas of predicted high density have higher counts than those from areas of predicted low density. In particular: embayments have higher relative densities than more open sites; there is higher densities on sites located on the western side of the loch compared to the east; due to wind forcing lice densities are higher in bays where lice catch the prevailing wind.

\section{DISCUSSION AND CONCLUSIONS}

The coupled hydrodynamic-particle Loch Linnhe model is in an early stage of validation. It indicates that the model framework developed for the small Loch Torridon is usable in the larger more complex system of Loch Linnhe and the technical issues of adaption of the model have been solved.

The process of validation is far more difficult than for the smaller loch, largely because of the difficulty and expense of obtaining data to carry out this validation. However, it has proven possible to obtain useful data even under very adverse conditions.

The initial results indicate lice can be transported over large distances (up to $30 \mathrm{~km}$ before becoming infectious) and that farms may be exposed to elevated infection pressure over these distances. However, the lice are often very locally concentrated and farms that are in close proximity to each other may not interact in this way at all. The results are consistent with those obtained in Loch Torridon but transmission distances are on a much larger scale.

Although there are few sentinel cage sites the general trends predicted by the model agree with the observations for regions within the system. The processing of samples from plankton tows are currently being undertaken and will be used to assess the model predictions in the same way as the caged fish data. .

Further work has to be done on validation of the model under more real forcing scenarios, multiple release points during run dates and point releases within these dates. It is also possible that a new model geometry based on FVCOM with variable element sizes may usefully extend the model domain into side lochs and the Sound of Mull. Work led by SAMS is currently being undertaken, with MSS advice, to adapt the lice particle model to an FVCOM geometry in Loch Fyne another large sea loch south of Loch Linnhe. 
The scaling up of the model from a small loch system to the larger system demonstrates that the model framework could be applied to a wide range of loch systems where there are detailed hydrodynamic models. A model which predicts the distribution and relative abundance of salmon lice could be used to measure the background distribution of lice without the presence of fish farms in a system, contributing towards the planning process for siting of new farms, whilst also being used to investigate how new sites may alter the distribution in a system The modelled distributions could be used to measure the relationship between interconnected farms, enabling managers to have more informed surveillance and treatment regimes. The modelled dispersal distances could contribute towards restructuring of disease management areas for the control of pathogens. The model could also be used to provide information on potential releases of lice from other locations such as processing plants or transport vessels.

\section{ACKNOWLEDGMENTS}

The POLCOMS model used for hydrodynamics was developed by SAMS; data has been collected by fish farmers, local fisheries trusts and by scientists from MSS. SAMS kindly provided wind data from their weather station. We especially thank Michael Penston, Campbell Pert and Stuart Wallace for collection of data under adverse conditions, and the help of boat crews on various vessels. Thanks also go to Marine Harvest Scottish Sea Farms, the Underwater Centre, Duart Castle and Mr. Malcolm for their help. The project is funded by the Scottish Government under project AQ0040 which is led by Catherine Collins of MSS.

\section{REFERENCES}

Amundrud, T.L., \& Murray, A.G. (2009) Modelling sea lice dispersion under varying environmental forcing in a Scottish sea loch. Journal of Fish Diseases, 32, 27- 44.

Bricknell, I. R., Dalesman, S. J., O’Shea, B., Pert, C. C. \& Mordue Luntz, A. J. (2006) Effect of environmental salinity on sea lice Lepeophtheirus salmonis success. Diseases of Aquatic Organisms, 71, 201-212.

Costell, M.J. (2009) The global economic cost of sea lice to the salmonid farming industry. Journal of Fish Diseases, 32, $115-118$.

Gargan, P., Tully, O. and Poole, W. (2007) Relationship Between Sea Lice Infestation, Sea Lice Production and Sea Trout Survival in Ireland, 1992-2001, in Salmon at the Edge (ed D. Mills), Blackwell Science Ltd., Oxford.

Hevrøy E.M., Boxaspen K., Oppedal F., Taranger G.L. \& Holm J.C. (2003) The effect of artificial light treatment and depth on the infestation of the sea louse, Lepeophtheirus salmonis on Atlantic salmon (Salmo salar L.) culture. Aquaculture, 220, 1-14.

Johnson S.C. \& Albright L.J. (1991) Development, growth, and survival of Leopeophtheirus salmonis (Copepoda: Caligidae) under laboratory conditions. Journal of the Marine Biological Association of the United Kingdom, 71, 425-463.

Krkošek, M. \& Hilburn, R. (2011) Sea lice (Lepeophtheirus salmonis) infestations and the productivity of pink salmon (Oncorhynchus gorbuscha) in the Broughton Archipelago, British Columbia, Canada. Canadian Journal of Fisheries and Aquatic Sciences, 68, $17-29$.

Lees, F., Gettinby, G. \& Revie, C.W. (2008) Changes in epidemiological patterns of sea lice infestation on farmed Atlantic salmon (Salmo salar L.) in Scotland between 1996 and 2006. Journal of Fish Diseases, 31, $251-262$

Murray, A.G. \& Amundrud, T.L. (2007) Using coupled biophysical - particle tracking models of sea lice in Loch Torridon. Proceedings of the International Congress on Modelling and Simulation. Christchurch, New Zealand, December 2007, 2848-2853.

Penston, M.J. \& Davies, I.M (2009) An assessment of salmon farms and wild salmonids as sources of Lepeophtheirus salmonis (Krøyer) copepodids in the water column in Loch Torridon, Scotland. Journal of Fish Diseases, 32, 75-88.

SSPO (2011) Scottish salmon producers' organisation annual report 2010. Accessed 9 Jun. 2011 http://www.scottishsalmon.co.uk/userFiles/885/Annual_report_april_2011.pdf

Stein, A., Bjorn, P.A., Heuch, P.A., \& Elston, D.A. (2005) Population dynamics of salmon lice Lepeophtheirus salmonis on Atlantic salmon and sea trout. Marine Ecology Progress Series, 290, 263 - 275.

Walker, A.J. (2010) Scottish farms annual production survey 2009 Accessed 9 Jun. 2011 www.scotland.gov.uk/Resource/Doc/295194/0106192.pdf 